\title{
OBTENÇÃO DE CURVAS DE RUPTURA NA ADSORÇÃO DO AZUL DE METILENO EM CARVÃO ATIVADO DO ENDOCARPO DO COCO
}

\author{
K. R. B. MELO ${ }^{1}$, R. G. S. A. ANDRADE ${ }^{1}$, F. D. S. BARBOSA ${ }^{1}$, J. I. SOLETTI ${ }^{1}$ e S. H. V. \\ CARVALHO $^{1}$ \\ ${ }^{1}$ Universidade Federal de Alagoas, Centro de Tecnologia (CTEC) \\ E-mail para contato: karlaraphaelamelo@gmail.com
}

\begin{abstract}
RESUMO - A adsorção é o processo no qual uma substância líquida ou gasosa, adsorbato, fica retida à superfície de um sólido, adsorvente. É influenciada principalmente pela morfologia, composição e características físico-químicas do adsorvente e pela composição e concentração inicial do adsorbato. Este trabalho objetivou a obtenção das curvas de ruptura de adsorção do azul de metileno em carvão ativado do endocarpo do coco e avaliação da eficiência desse adsorvente para a remoção do corante. Os experimentos foram realizados em uma coluna de leito fixo, variando as concentrações iniciais da solução de azul de metileno em 50,70 e $100 \mathrm{ppm}$. Foram fixados a quantidade de adsorvente, $10 \mathrm{~g}$, altura do leito, $8,89 \mathrm{~cm}$, tempo de corrida, $30 \mathrm{~min}$, e rotação da bomba, $5 \mathrm{rpm}$; As análises de absorbância das alíquotas retiradas no decorrer dos experimentos foram obtidas por espectroscopia e a partir delas calcularam-se as concentrações. Os resultados das curvas de Breakthrough indicaram uma variação não linear do tempo de ruptura, sendo esse menor para a solução de $100 \mathrm{ppm}$. O tempo de saturação não foi evidenciado para nenhuma das soluções. Os percentuais de remoção demostraram a maior capacidade adsortiva do carvão ativado para solução de 50 ppm. Os resultados obtidos mostram que o carvão ativado proveniente do endocarpo do coco é um adsorvente altamente eficaz e indicam que, para as condições operacionais adotadas, a faixa ideal de atuação desse adsorvente se dá para as soluções de 50 e 70 ppm.
\end{abstract}

\section{INTRODUÇÃO}

\subsection{Adsorção}

A adsorção é um processo de transferência de massa onde um ou mais constituintes de uma mistura fluida ficam retidos à superfície de um sólido. A migração de uma espécie da fase fluida para a superfície do sólido adsorvente só é possível devido à diferença de concentração que existe entre o adsorbato no seio da solução e na superfície do adsorvente, sendo esta considerada a força motriz para o processo de adsorção (McCabe et al., 1998).

São vários os fatores que influenciam o processo de adsorção, como a área superficial específica, visto que este é um fenômeno de superfície e, para partículas maiores, a resistência à difusão é menor e grande parte da superfície interna da partícula não é disponibilizada para 
adsorção (Sekar et al., 2004). Outros fatores importantes são a porosidade, o volume específico e o tamanho de poros, os grupos funcionais presentes na superfície do adsorvente, a natureza do material precursor, além do $\mathrm{pH}$ e da temperatura. Outra característica de forte influência é a concentração inicial do absorbato, visto que quanto maior a concentração inicial, maior é a quantidade de moléculas competindo para se adsorverem na superfície do adsorvente (Domingues, 2005).

\subsection{Carvão Ativado}

O carvão ativado é um adsorvente que se caracteriza como um sólido de forma microcristalina, não grafítica de carbono. Apresenta-se predominantemente amorfo na forma de pó ou granulado, o que consiste a ele uma elevada área superficial e alta porosidade e essas características lhe oferecem uma elevada capacidade de adsorção.

As principais propriedades dos carvões ativados são a área superficial, estrutura dos poros, propriedades eletroforéticas e acidez superficial, as quais são distribuídas de acordo com o tipo de material e a maneira de ativação do carvão (Amaral, 1984). Essa ativação envolve tratamento térmico, com a presença de agentes químicos ou por métodos físicos (gasificação controlada). A preparação do carvão ativado pelo método físico ou químico é um ponto industrialmente muito importante. De uma maneira geral, quase todos os compostos com alto teor de carbono podem ser transformados em carvões ativados.

\subsection{Azul de Metileno}

O azul de metileno é um corante catiônico da classe das fenotiazinas muito empregado em áreas biológicas, médicas e, principalmente, na indústria têxtil no tingimento de tecidos de algodões e lãs. Quando não tratado adequadamente, o lançamento não controlado em rios e lagos afeta a transparência das águas, como também compromete a atividade fotossintética natural, provocando alterações e toxicidade na biota aquática. Em virtude dessas consequências, torna-se necessário um tratamento prévio de seus despejos antes do lançamento em corpos receptores (Kunz et al., 2002; Silva \& Oliveira, 2012). Nesse contexto, o método da adsorção vem sendo muito empregado no tratamento desses efluentes corados devido ao seu baixo custo e facilidade de operação; esta técnica se baseia na remoção desses contaminantes pela interação entre o corante com algum material adsorvente.

\section{METODOLOGIA}

\section{O carvão ativado utilizado foi da marca CarbonMar Carvão Ativado.}

Para avaliar a capacidade de remoção do azul de metileno pelo carvão ativado do endocarpo do coco, os ensaios de adsorção foram realizados utilizando-se $10,0 \mathrm{~g}$ de adsorvente com soluções de 50, 70 e 100 ppm de azul de metileno. Para isso, utilizou-se um sistema composto por uma bomba peristáltica, operando com uma velocidade de $5 \mathrm{rpm}$, e uma coluna de adsorção de leito fixo de $8,89 \mathrm{~cm}$ de altura e $1,93 \mathrm{~cm}$ de diâmetro. Com auxílio de um cronômetro, constatou-se o tempo de residência de cada uma das soluções. E ainda, para cada uma das corridas experimentais coletaram-se alíquotas da corrente de saída da solução de azul de metileno nos tempos $0,3,5,10,15,20,25$ e 30 minutos. 
Após coletar as amostras, as mesmas foram analisadas no espectrofotômetro para obter a absorbância das soluções no decorrer da adsorção. A absorbância foi convertida em concentração de azul de metileno com auxílio da curva padrão desse adsorbato, construída medindo absorbâncias de 5 soluções padrão de azul de metileno de concentrações conhecidas, preparadas a partir de uma solução concentrada.

\section{RESULTADOS} 1.

Os tempos de residência de cada uma das soluções encontram-se dispostos na Tabela

Tabela 1 - Tempo de residência das soluções de 50, 70 e 100 ppm de azul de metileno

\begin{tabular}{|c|c|}
\hline $\begin{array}{c}\text { Solução de azul } \\
\text { de metileno } \\
(\mathrm{ppm})\end{array}$ & $\begin{array}{c}\text { Tempo de } \\
\text { residência (s) }\end{array}$ \\
\hline \hline 50 & 56 \\
\hline 70 & 70 \\
\hline 100 & 81 \\
\hline
\end{tabular}

Infere-se dos tempos de residência obtidos que o tempo necessário para a solução atravessar a coluna de adsorção é maior para concentrações iniciais de adsorbato mais elevadas.

A partir dos dados de absorbância pôde-se calcular as concentrações das soluções de 50, 70 e 100 ppm de azul de metileno no decorrer da adsorção através da curva padrão do adsorbato, dada pela Equação 1 .

$$
C=(A B S-0,02) / 0,2404
$$

Os valores de absorbâncias e concentrações das soluções encontram-se dispostos na Tabela 2.

Tabela 2 - Dados de absorbância e concentração das soluções de azul de metileno

\begin{tabular}{|c|c|c|c|c|c|c|}
\hline & \multicolumn{2}{|c|}{$50 \mathrm{ppm}$} & \multicolumn{2}{c|}{$70 \mathrm{ppm}$} & \multicolumn{2}{c|}{$100 \mathrm{ppm}$} \\
\hline \hline $\begin{array}{c}\text { Tempo } \\
(\mathrm{min})\end{array}$ & Absorbância & $\begin{array}{c}\text { Concentração } \\
(\mathrm{ppm})\end{array}$ & Absorbância & $\begin{array}{c}\text { Concentração } \\
(\mathrm{ppm})\end{array}$ & Absorbância & $\begin{array}{c}\text { Concentração } \\
(\mathrm{ppm})\end{array}$ \\
\hline 0 & 0,143 & 0,512 & 0,28 & 1,082 & 0,504 & 2,013 \\
\hline 3 & 0,108 & 0,366 & 0,21 & 0,790 & 1,587 & 6,518 \\
\hline 5 & 0,09 & 0,291 & 0,127 & 0,445 & 1,996 & 8,220 \\
\hline 10 & 0,093 & 0,304 & 0,119 & 0,412 & 3,032 & 12,529 \\
\hline 15 & 0,1 & 0,333 & 0,139 & 0,495 & 9,2 & 38,186 \\
\hline 20 & 0,256 & 0,982 & 0,633 & 2,550 & 13,7 & 56,905 \\
\hline 25 & 0,67 & 2,704 & 1,98 & 8,153 & 14,05 & 58,361 \\
\hline 30 & 0,748 & 3,028 & 2,548 & 10,516 & 15,95 & 66,265 \\
\hline
\end{tabular}


Percebe-se, pelos dados de absorbância que, para a soluções de 50 e 70 ppm, houve uma pequena redução da absorbância do azul de metileno nos valores das primeiras alíquotas. Esse fato pode ser justificado possivelmente pelo arraste de carvão ativado nos primeiros minutos da adsorção.

De posse dos resultados, construíram-se as curvas de ruptura para cada uma das corridas experimentais, conforme a Figura 1.

Figura 1 - Curvas de ruptura das soluções de 50, 70 e 100 ppm.
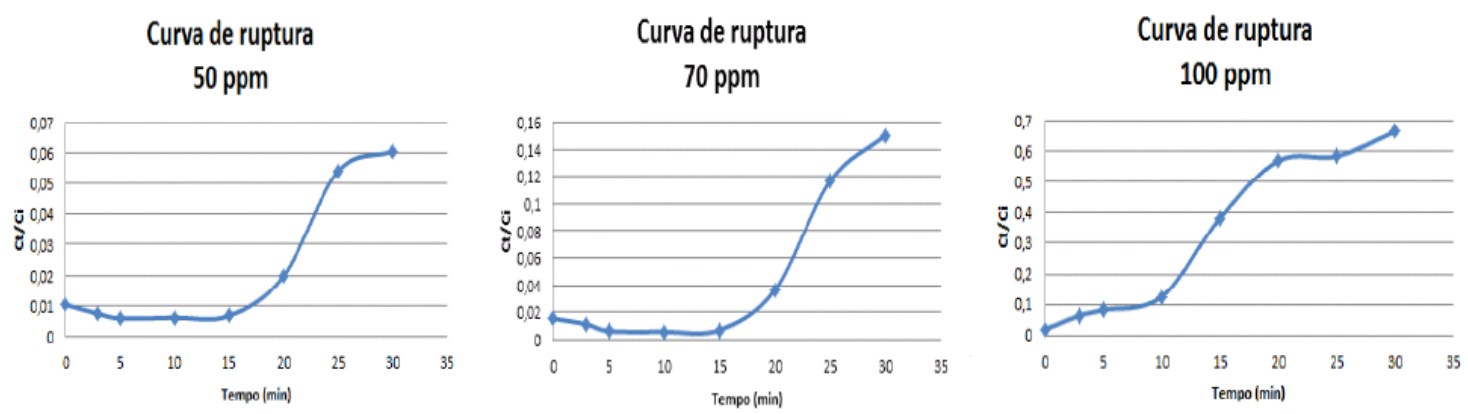

As curvas de ruptura representam o movimento progressivo da zona de transferência de massa no leito. O tempo de breakthrough é definido como o tempo para que a concentração de efluente final seja de $10 \%$ da inicial (Oliveira, 2009). Como se pode observar da Figura 1, esse tempo diminui com o aumento da concentração inicial da solução, sendo assim, o breakthrough ocorre mais rapidamente para a solução de maior concentração. Tanto que para as corridas experimentais de mesma duração, identificam-se os tempos de ruptura somente nas curvas de breakthrough das soluções de 70 e 100 ppm, sendo igual a, aproximadamente, 24 e 9 minutos, respectivamente. Quanto ao tempo de saturação, infere-se que o mesmo não foi atingido ao longo dos 30 minutos, visto que nenhum dos estudos de absorção realizado obteve uma concentração final do efluente igual a $90 \%$ da inicial. No entanto, as curvas de ruptura estiveram todas bem delineadas e os resultados obtidos para esse tempo de adsorção comprovam a eficiência do carvão ativado do endocarpo do coco como adsorvente.

Infere-se ainda dos resultados, que as curvas de ruptura das soluções de menor concentração apresentam comportamentos semelhantes e possuem inclinações mais discretas, enquanto a curva da solução de maior concentração, igual a 100 ppm, apresenta um declive acentuado. Explica-se esse comportamento, pois, com o aumento da concentração inicial, há um maior número de moléculas para serem adsorvidas, ocorrendo mais rapidamente a saturação.

Com as concentrações das soluções no decorrer da adsorção, calculou-se o percentual de remoção de cada amostra utilizando a Equação 2 e os resultados obtidos estão dispostos na Tabela 3. A partir desses dados construiu-se o gráfico apresentado na Figura 2, que permite avaliar a capacidade de adsorção do carvão ativado nas diferentes corridas.

$$
\%=\frac{C_{i}-C_{t}}{C_{i}} \times 100
$$


Tabela 3 - Percentuais de remoção das amostras das soluções de 50, 70 e 100 ppm de azul de metileno

\begin{tabular}{|c|c|c|c|}
\hline & $50 \mathrm{ppm}$ & $70 \mathrm{ppm}$ & $100 \mathrm{ppm}$ \\
\hline $\begin{array}{c}\text { Tempo } \\
(\min )\end{array}$ & $\begin{array}{c}\text { Percentual de remoção } \\
(\%)\end{array}$ & $\begin{array}{c}\text { Percentual de remoção } \\
(\%)\end{array}$ & $\begin{array}{c}\text { Percentual de remoção } \\
(\%)\end{array}$ \\
\hline 0 & 98,977 & 98,455 & 97,987 \\
\hline 3 & 99,268 & 98,871 & 93,482 \\
\hline 5 & 99,417 & 99,364 & 91,78 \\
\hline 10 & 99,393 & 99,412 & 87,471 \\
\hline 15 & 99,334 & 99,293 & 61,814 \\
\hline 20 & 98,037 & 96,357 & 43,095 \\
\hline 25 & 94,592 & 88,353 & 41,639 \\
\hline 30 & 93,943 & 84,977 & 33,735 \\
\hline
\end{tabular}

Figura 2 - Percentual de remoção em função do tempo.

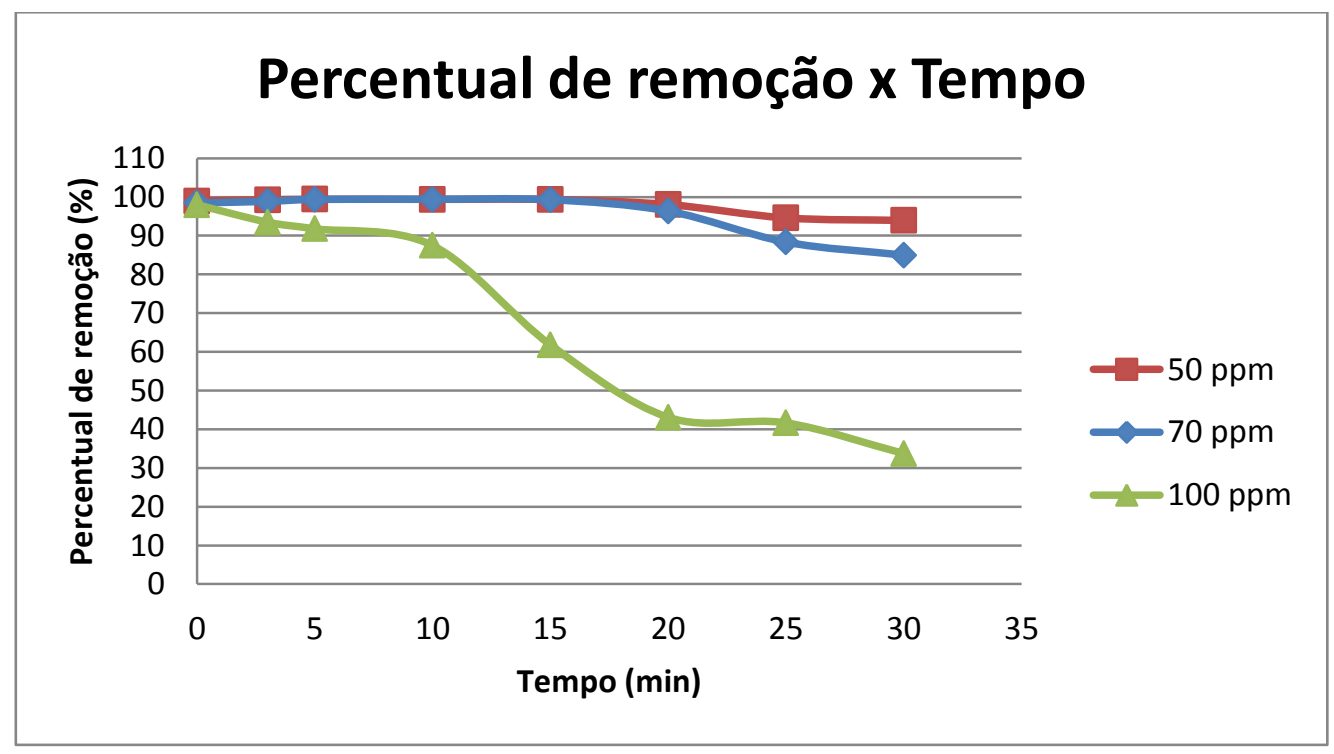

Da Figura 2, percebe-se que os melhores percentuais de remoção foram observados para a solução de menor concentração inicial, reafirmando a conclusão de que a concentração inicial da solução afeta a taxa de saturação do adsorvente. Constata-se ainda que para soluções com maiores concentrações, o percentual de remoção reduz significativamente no decorrer da adsorção, evidenciando a rápida saturação do carvão ativado nessas condições de operação.

\section{CONCLUSÕES}

Das curvas de ruptura, percebe-se que o aumento do tempo de Breakthrough não é linear e que o mesmo diminui na ordem de $62,5 \%$ quando se aumenta a concentração de 70 para $100 \mathrm{ppm}$. Como consequência, afirma-se que o tempo de ruptura de soluções mais 
concentradas é menor que os de soluções mais diluídas. E ainda, percebe-se que a saturação do adsorvente é mais lenta quanto menor for a concentração inicial.

A partir dos resultados do percentual de remoção, percebe-se a eficiência do carvão ativado para as soluções de 50 e $70 \mathrm{ppm}$. O que permite comprovar que a faixa de estudo foi adequada para a ótima atuação do adsorvente. No entanto, para a solução de 100 ppm, os resultados demonstram uma rápida saturação do adsorvente, indicando que para concentrações maiores o dimensionamento da coluna utilizada é inadequado para essas condições operacionais, comprometendo a eficiência do carvão ativado. Melhores resultados poderiam ser proporcionados variando os parâmetros de vazão, $\mathrm{pH}$ e temperatura, mesmo para concentrações mais altas.

\section{NOMENCLATURA}
ABS - Absorbância
$\mathrm{C}_{\mathrm{i}-\text { Concentração inicial da solução }}$
$\mathrm{C}_{\mathrm{t}-}$ Concentração da solução no instante de tempo $\mathrm{t}$

\section{REFERÊNCIAS}

AMARAL, S. T. Remoção de Metais Pesados de Efluentes Industriais por Adsorção em Coque Poroso. Tese (Doutorado) - Programa de Pós-Graduação em Ecologia. UFRGS. Porto Alegre. 1984.

DOMINGUES, V. M. F. Utilização de um produto natural (cortiça) como adsorvente de pesticidas piretróides em águas. 2005. 224 f. Tese (Doutorado em Engenharia Química) - Faculdade de Engenharia da Universidade do Porto, Porto. 2005.

KUNZ, A.; ZAMORA, P. P.; MORAES, S. G.; DURÁN, N. Novas tendências no tratamento de efluentes têxteis. Química Nova, v.25, p.78-82, 2002.

McCABE, W. L. M.; SMITH, J. C.; HARRIOTT, P. Operaciones Unitarias en Ingenieria Quimica: Edigrafos, S.A. Spain, 1998.

OLIVEIRA, P. S. A. Remoção de azul de metileno numa coluna de adsorção com enchimento de casca de noz carbonizada. Tese (Mestrado) - Faculdade de Engenharia da Universidade do Porto, Porto. 2009.

SEKAR, M.; SAKTHI, V.; RENGARAJ, S. Kinetics and equilibrium adsorption study of lead (II) onto activated carbon prepared from coconut shell. Colloid and Interface Science, v. 279 , p. 307-313, 15 nov. 2004. 